\title{
General anesthesia for cesarean section in the presence of mitral stenosis associated with severe pulmonary hypertension
}

\author{
Usha V. Bansal ${ }^{1 *}$, Varun V. Bansal' ${ }^{2}$, Bhavesh R. Patel ${ }^{1}$ \\ ${ }^{1}$ Department of Anesthesiology, Apollo Hospital, Gandhinagar, Gujarat, India \\ ${ }^{2}$ Undergraduate Medical Student, Seth G.S.M.C and K.E.M Hospital, Mumbai, Maharashtra, India
}

Received: 31 August 2020

Accepted: 06 October 2020

\author{
*Correspondence: \\ Dr. Usha V. Bansal, \\ E-mail: ushavbamd@gmail.com
}

Copyright: () the author(s), publisher and licensee Medip Academy. This is an open-access article distributed under the terms of the Creative Commons Attribution Non-Commercial License, which permits unrestricted non-commercial use, distribution, and reproduction in any medium, provided the original work is properly cited.

\begin{abstract}
Rheumatic heart disease (RHD) is the most common cause of cardiac disease during pregnancy in India. A case of severe pulmonary hypertension (pulmonary arterial pressure- $98 \mathrm{~mm} \mathrm{Hg}$ ) secondary to mitral stenosis associated with RHD in a 28-year old woman, is described. She underwent a high risk elective cesarean section under general anesthesia at 36 weeks of gestation. The intraoperative and postoperative course was uneventful. The advantages of general anesthesia over neuraxial blockade during cesarean section are discussed in this report. The management of patients at a high risk of developing pulmonary edema and decompensated heart failure in the perioperative period has been stressed upon. A thorough understanding of the pathophysiology and complications of RHD during pregnancy and cesarean section is required for managing the disease successfully.
\end{abstract}

Keywords: Rheumatic heart disease, Cesarean section, General anesthesia, Pulmonary hypertension

\section{INTRODUCTION}

The physiological hemodynamic changes in pregnancy which are usually tolerated well by expectant mothers can be disastrous in patients with heart disease. We present a case of rheumatic heart disease with moderate mitral stenosis associated with severe pulmonary hypertension, with a focus on the use of general anesthesia during cesarean section. Its merits and demerits in comparison with epidural anesthesia have been discussed, the latter being commonly advocated in cesarean sections for patients suffering from heart diseases.

\section{CASE REPORT}

A 28-year-old female, G4P1L1A1FTND1, was referred to our center at 33 weeks of gestation with complaints of dyspnoea on exertion, orthopnoea, and pedal edema. Her echocardiographic findings showed mitral stenosis (mitral valve area-1.1 cm2), left atrial enlargement, and severe pulmonary hypertension ( $98 \mathrm{~mm} \mathrm{Hg}$ ), along with severe tricuspid regurgitation and aortic regurgitation. An abdominal ultrasonography (USG) scan revealed mild intrauterine growth retardation. For symptomatic relief, she was started on digoxin, atenolol, and torsemide.

At 36 weeks of gestation, the patient, weighing $48 \mathrm{~kg}$, was taken up for an elective cesarean section after taking a 'high-risk' informed consent. She received preoperative antibiotic prophylaxis for infective endocarditis. A central venous line, an arterial line, and a Foley's catheter were inserted. While pre-oxygenating the patient, she was painted and draped, in order to shorten the anesthesia-todelivery time. Propofol (1\%, $100 \mathrm{mg}$ intravenous-IV) and succinylcholine (100 mg IV) were given for induction of anesthesia. Endotracheal intubation was carried out. At this stage, anesthesia was maintained with oxygen-air and sevoflurane $(3 \%)$. Within two minutes a healthy male child was delivered, with APGAR scores 9/10 at one minute and five minutes. Once the umbilical cord was clamped fentanyl (two doses of $50 \mu \mathrm{g}$ each 5 minutes apart IV) and atracurium were given. An oxytocin infusion was started. 
At this stage, injection furosemide (20 mg IV) was given to prevent volume overload after the delivery of the baby. The heart rate, blood pressure, and oxygen saturation were within normal limits throughout the intraoperative period.

At the end of the surgery, the patient was de-curarized with neostigmine along with glycopyrrolate. After extubation, the patient was shifted to the cardiac intensive care unit (ICU), where digoxin was resumed and deep venous thrombosis prophylaxis was started. The postoperative period was uneventful and she was discharged on the fifth postoperative day, with advice to follow up with a cardiologist for further line of management.

\section{DISCUSSION}

Worldwide, the prevalence of heart disease during pregnancy is estimated to be approximately $1 \%$, with RHD being the most common etiology in developing countries including India. ${ }^{1}$ Mitral stenosis secondary to RHD results in an elevation of the left atrial pressure. This is transmitted retrogradely into the pulmonary circulation, leading to pulmonary hypertension. If not treated, right heart failure ensues, as witnessed by the presence of bilateral pedal edema and tricuspid regurgitation in our patient. The course of the disease may be complicated further by pulmonary edema, arrhythmias, bacterial endocarditis, thromboembolic phenomena, intrauterine growth retardation, abortions, and preterm labor.

\section{Antenatal management}

According to the modified World Health Organization (WHO) classification of maternal cardiovascular risk, pulmonary hypertension due to any cause is considered under a class 4 risk group. ${ }^{2}$ Medical termination of pregnancy (MTP) is recommended in such patients due to the high risk of maternal and fetal mortality, but it could not be performed in our patient as she presented at 33 weeks of gestation. Heart rate reduction with beta-blockers forms the cornerstone of antepartum management in symptomatic patients with mitral stenosis, as tachycardia leads to a reduction in the left ventricular diastolic filling time, hence reducing the preload and cardiac output subsequently. ${ }^{3}$

The cardiovascular alterations during labor that can precipitate pulmonary edema in patients with mitral stenosis include an increase in heart rate, an increase in circulating blood volume due to uterine contractions, and acute changes in cardiac output and venous return. ${ }^{4}$ Cesarean section shortens the delivery time and reduces the hemodynamic changes caused by uterine contractions. ${ }^{5}$ Hence, an elective cesarean section was preferred over vaginal delivery in our case.

\section{Anesthetic management}

Epidural anesthesia is commonly advocated for cesarean sections in patients with heart diseases because it is associated with a gradual onset of sympathetic blockade, preventing rapid peripheral vasodilation and subsequent hypotension, which may occur when spinal anesthesia is used. ${ }^{6}$ Gradual vasodilation decreases the preload on the heart, reducing the chances of heart failure and pulmonary edema. ${ }^{7}$ However, patients who develop right heart failure secondary to mitral stenosis may not be able to maintain adequate cardiac output if the preload is decreased excessively. The prior adrenergic blockade and diuretic therapy can worsen the tendency to develop hypotension in such patients. ${ }^{7}$ Considering the history of right heart failure in our patient, we avoided epidural anesthesia.

When general anesthesia is used, the ventilatory status of the patient can be controlled meticulously. 8 This is necessary for patients at a high risk of pulmonary edema. It is also preferred in patients receiving anticoagulation in the peripartum period, who are at risk of developing an epidural hematoma, a complication of epidural anesthesia. ${ }^{9}$ Considering these factors, we preferred using general anesthesia in our case. Sevoflurane was preferred due to its ability to control the stress response adequately. ${ }^{10}$ Rapid sequence anesthesia without premedication (except the inducing agent) decreases the risk of neonatal respiratory depression. 8 Keeping this in mind, we administered fentanyl after clamping the cord, not before it.

\section{Post-operative care}

Autotransfusion of blood due to uterine contraction following the delivery of the baby increases the risk of cardiac decompensation in the immediate postoperative period. ${ }^{10}$ Hence, patients with severe heart diseases should be monitored postoperatively in a cardiac ICU.

\section{CONCLUSION}

Various hemodynamic parameters need to be taken into consideration to decide the appropriate form of anesthesia during cesarean section in patients with severe RHD. Such cases should be managed at a tertiary level center under the supervision of a multidisciplinary team consisting of an obstetrician, a cardiologist, an anesthesiologist, and a neonatologist.

\section{Funding: No funding sources Conflict of interest: None declared Ethical approval: Not required}

\section{REFERENCES}

1. French KA, Poppas A. Rheumatic Heart Disease in Pregnancy: Global Challenges and Clear Opportunities. Circulation. 2018;137(8):817-9.

2. Regitz-Zagrosek V, Roos-Hesselink JW, Bauersachs J, Blomström-Lundqvist C, Cífková R, De Bonis M, et al. ESC Scientific Document Group. 2018 ESC Guidelines for the management of cardiovascular 
diseases during pregnancy. Eur Heart J. 2018;39(34):3165-241.

3. Weiner MM, Vahl TP, Kahn RA. Case scenario: Cesarean section complicated by rheumatic mitral stenosis. Anesthesiology. 2011;114(4):949-57.

4. Pan PH, D'Angelo R. Anesthetic and analgesic management of mitral stenosis during pregnancy. Reg Anesth Pain Med. 2004;29(6):610-5.

5. Gomar C, Errando CL. Neuroaxial anaesthesia in obstetrical patients with cardiac disease. Curr Opin Anaesthesiol 2005;18(5):507-12.

6. Choudhury M. Neuraxial anaesthesia in parturient with cardiac disease. Indian J Anaesth. 2018;62(9):682-90.

7. Kocum A, Sener M, Calıskan E, Izmirli H, Tarım E, Kocum $\mathrm{T}$, et al. Epidural anesthesia for cesarean section in a patient with severe mitral stenosis and pulmonary hypertension. J Cardiothorac Vasc Anesth. 2010;24(6):1022-3.
8. Arendt KW, Lindley KJ. Obstetric anesthesia management of the patient with cardiac disease. Int J Obstet Anesth. 2019;37:73-85.

9. Rex S, Devroe S. Anesthesia for pregnant women with pulmonary hypertension. Curr Opin Anaesthesiol. 2016;29(3):273-81.

10. Kela M, Buddhi M. Combined mitral and aortic stenosis in parturient: Anesthesia management for labor and delivery. J Anaesthesiol Clin Pharmacol. 2017;33(1):114-6.

Cite this article as: Bansal UV, Bansal VV, Patel BR. General anesthesia for cesarean section in the presence of mitral stenosis associated with severe pulmonary hypertension. Int J Reprod Contracept Obstet Gynecol 2020;9:4759-61. 